\title{
Neuronal Loss in the Rostral Ventromedial Medulla in a Rat Model of Neuropathic Pain
}

\author{
Mai Lan Leong, ${ }^{1 \star}$ Ming Gu, ${ }^{1 \star}$ Rebecca Speltz-Paiz, ${ }^{1}$ Eleanor I. Stahura, ${ }^{1}$ Neli Mottey, ${ }^{1}$ Clifford J. Steer, ${ }^{2}$ \\ and Martin Wessendorf ${ }^{1}$ \\ ${ }^{1}$ Department of Neuroscience, and 2Departments of Medicine and Genetics, Cell Biology and Development, University of Minnesota, Minneapolis, \\ Minnesota 55455
}

Cell death has been reported in the CNS in models of neuropathic pain (Sugimoto et al., 1990; Whiteside and Munglani, 2001; Scholz et al., 2005; Fuccio et al., 2009). In our present study, we examined the effects of spinal nerve ligation (SNL) on the number of neurons in the rostral ventromedial medulla (RVM), a brainstem region involved in modulation of nociception. In rats receiving SNL, we found that the number of RVM neurons decreased by $23 \%$ in the side ipsilateral to the surgery. The loss of RVM neurons was also associated with a bilateral increase in the number of glia as well as bilateral activation of both astrocytes and microglia. Administration of tauroursodeoxycholic acid (TUDCA), which reportedly inhibits apoptosis, significantly reduced the loss of neurons, the increase in glia, and the mechanical hypersensitivity induced by SNL.

Among RVM neurons, we found that serotonergic (5-hydroxytryptamine, 5-HT) neurons decreased by 35\% ipsilateral to SNL. Consistent with these findings, the density of 5-HT-immunoreactive varicosities in the superficial dorsal horn of the spinal cord was $15-30 \%$ lower, ipsilateral to SNL. To test the function of the remaining 5-HT neurons, we administered the 5-HT neurotoxin, 5,7dihydroxytryptamine (5,7-DHT). Interestingly, after 5,7-DHT, mechanical withdrawal thresholds increased significantly. We conclude that nerve injury induces death of antinociceptive RVM neurons that can be reduced or abolished by TUDCA. We propose that the loss of RVM neurons shifts the balance of descending control from pain inhibition to pain facilitation.

\section{Introduction}

Trauma or disease affecting peripheral nerves frequently results in the development of chronic, sometimes intractable, neuropathic pain. Existing treatments for neuropathic pain have limited effectiveness and produce relatively frequent adverse effects (Wallace, 2007). Therefore, understanding the basic mechanisms contributing to the generation and/or maintenance of neuropathic pain in preclinical animal models is key to providing predictable and efficient therapies in patient populations.

Studies have shown that enhanced pain induced by peripheral nerve injury is associated with increased spontaneous and evoked discharges from injured and/or adjacent nerves (Koltzenburg et al., 1992, 1994; Amir and Devor, 2000; Michaelis et al., 2000; Liu et al., 2001). Although this increased afferent discharge is vital in establishing spinal sensitization in the period immediately following nerve injury, the time course of such abnormal afferent

Received March 11, 2011; revised 0ct. 4, 2011; accepted 0ct. 6, 2011.

Author contributions: M.L.L., M.G., C.J.S., and M.W. designed research; M.L.L., M.G., R.S.-P., E.I.S., and N.M. performed research; C.J.S. contributed unpublished reagents/analytic tools; M.L.L. and M.G. analyzed data; M.L.L., M.G., C.J.S., and M.W. wrote the paper.

This work was supported by USPHS Grant DA017758 to M.W., Grant T32 DA 007234, the Minnesota Medical Foundation, and the Office of the Vice President for Research, University of Minnesota.

${ }^{*} M$.L.L. and M.G. contributed equally to this work.

Correspondence should be addressed to Martin Wessendorf, Department of Neuroscience, University of Minnesota, 321 Church Street SE, Minneapolis, MN 55455. E-mail: martinw@umn.edu.

M. Gu's present address: University of Maryland Dental School, Department Biomedical Sciences, 666 W Baltimore St, Room 5E-08, Baltimore, MD 21201.

DOI:10.1523/JNEUROSCI.1268-11.2011

Copyright $\odot 2011$ the authors $\quad 0270-6474 / 11 / 3117028-12 \$ 15.00 / 0$ activity is inconsistent with the long duration of heightened pain (Chaplan et al., 1994; Burgess et al., 2002; Porreca et al., 2002). It has been suggested that descending facilitation from the rostral ventromedial medulla (RVM), including its serotonergic (5hydroxytryptamine, 5-HT) neurons, may play an essential role by maintaining neuropathic pain after its initiation (Burgess et al., 2002; Suzuki et al., 2004; Vera-Portocarrero et al., 2006).

In studies where neuropathic pain is modeled by spinal nerve ligation (SNL) (Kim and Chung, 1992), microinjections of lidocaine into the RVM reduced the hypersensitivity observed after SNL (Pertovaara et al., 1996), as did ablation of populations of RVM neurons (Porreca et al., 2001), and lesions of the dorsolateral funiculus (DLF), in which RVM axons descend (Ossipov et al., 2000). In these studies, reversal of hypersensitivity was not observed immediately after nerve injury, but only several days later, consistent with a role for the RVM in the maintenance (but not initiation) of neuropathic pain.

Previous work has also suggested that apoptosis may play a role in the pathology of neuropathic pain. Apoptosis has been reported in dorsal root ganglia, the spinal dorsal horn and in cerebral cortex in models of neuropathic pain (Coggeshall et al., 2001; Whiteside and Munglani, 2001; Siniscalco et al., 2007; Fuccio et al., 2009; Sekiguchi et al., 2009). However, the loss of neurons has been disputed and its importance in neuropathic pain remains unclear (Polgár et al., 2004, 2005).

To help understand the importance of the RVM and its neurons in neuropathic pain, we examined RVM neurons and their spinal projections after SNL. We found that after SNL, the num- 

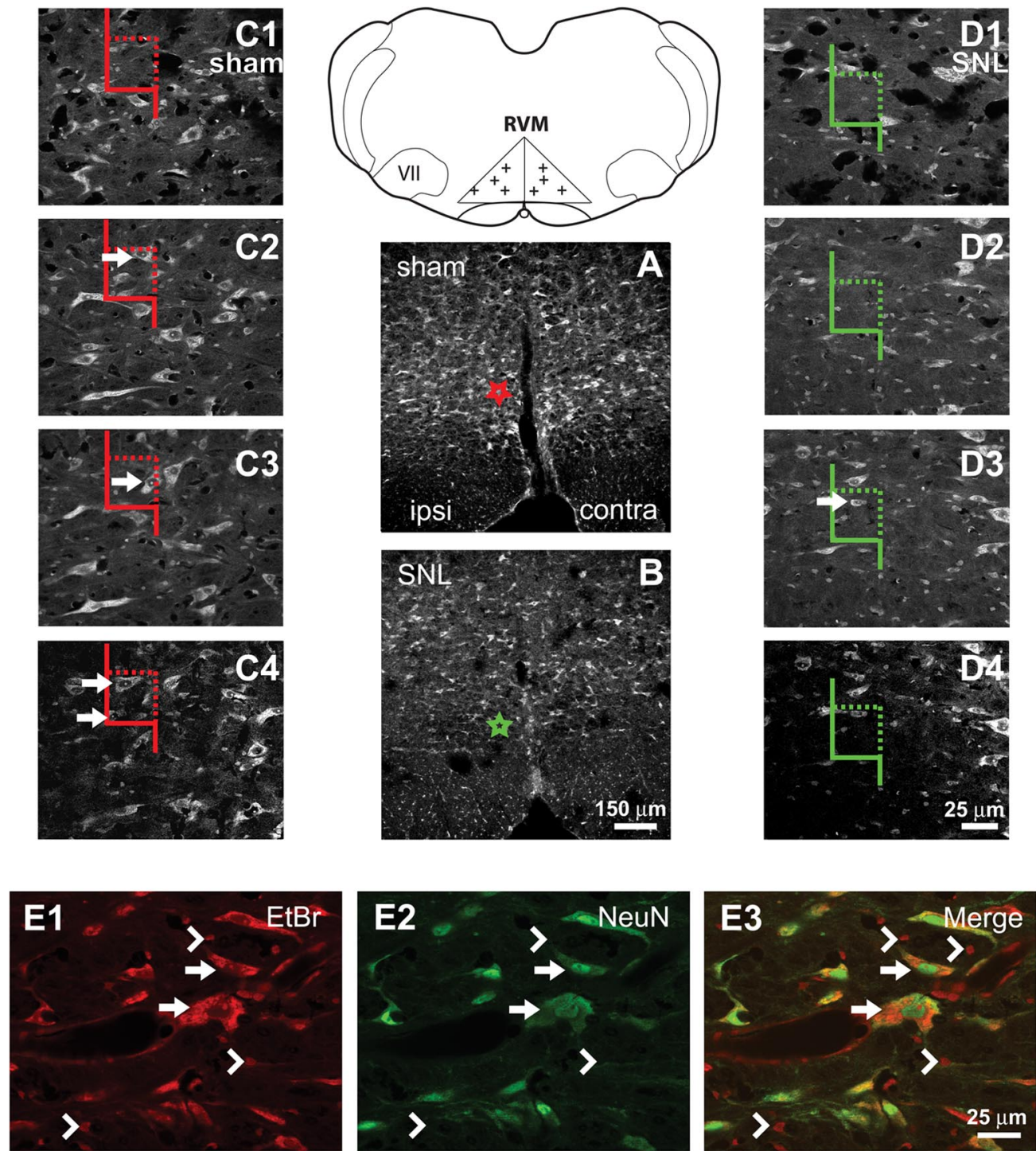

Figure 1. Definition of RVM and description of cell-counting methods. Line diagram: The RVM was defined as an isosceles triangle, the base of which was the width of the pyramidal tracts. The height of the triangle on the midline was half the width of the base. VII, facial nucleus. Crosses mark examples of randomly selected points used for cell counting. $\boldsymbol{A}, \boldsymbol{B}$, Nissl-stained sections from sham-treated and SNL-treated rats, respectively. Fewer RVM neurons were observed in rats after SNL. Stars in $\boldsymbol{A}$ and $\boldsymbol{B}$ represent the locations of the counting frames in $\boldsymbol{C}$ and $\boldsymbol{D}$, respectively. $\boldsymbol{C}, \boldsymbol{D}$, Examples of high-magnification sequences of images through the thickness of tissue sections used for cell counting. Color of counting frames corresponds to the color of the stars in $\boldsymbol{A}$ and $\boldsymbol{B}$. Arrows indicate neurons that would be counted. A neuron might appear in multiple images through the thickness of a section but was only counted when its nucleolus was first observed. Neurons were counted if their nucleoli fell entirely within the counting frame, or if they were partially within the counting frame without being in contact with a rejection line (solid line). E1-E3, Comparison of Nissl and NeuN labeling. Arrows indicate Nissl-stained neurons that were also NeuN-IR. Arrowheads indicate Nissl-stained glia that were not NeuN-IR. Cells with dark cytoplasm, a vacuous nucleus and a dark nucleolus (the Nissl criteria we used for a neuron) were always labeled for NeuN. Scale bar in B applies to $\boldsymbol{A}$ and $\boldsymbol{B}$. Scale bar in D4 applies to C1-C4 and D1-D4. Scale bar in E3 applies to E1-E3.

bers of RVM neurons (including 5-HT neurons) were significantly reduced. Our findings suggest that the pathology of neuropathic pain may be due in part to death of antinociceptive RVM neurons, leading to decreased descending inhibition of nociception.

\section{Materials and Methods}

Animals. Male Sprague Dawley rats (150-250 g; Harlan) were used for these studies; three to 10 animals were used for each experimental group. All experiments and procedures were performed using protocols approved by the University of Minnesota Institutional Animal Care and Use Committee.

SNL surgery. Rats were divided into two experimental groups: a group in which the L5 spinal nerve was ligated and cut (Blenk et al., 1997; Ringkamp et al., 1999; Li et al., 2000), and a sham-operated control group. The left L5 spinal nerve was isolated, tightly ligated and cut distal to the ligation under isoflurane anesthesia (1.5\%). The surgical procedure for the sham-operated group was identical to that of the SNL group, except that the L5 spinal nerve was not ligated or cut. General behavior of the rats was monitored before and after the surgery. Any rats showing difficulty elevating a hindpaw were discarded from the study.

Drug treatments. Rats were treated with 5,7-dihydroxytryptamine (5,7-DHT: $100 \mu \mathrm{g} / 10 \mu \mathrm{l}$, intracisternal injection) to induce loss of RVM 5-HT neurons. Rats were randomly assigned to one of four groups for these experiments: (1) L5 SNL with 5,7-DHT; (2) L5 SNL with vehicle injection; (3) sham with 5,7-DHT; and (4) sham with vehicle. Injections were given $10 \mathrm{~d}$ after surgery; animals receiving vehicle injections received sterile saline (10 $\mu$ l, intracisternal injection). To prevent damage to noradrenergic (NE) neurons, we pretreated animals $30 \mathrm{~min}$ before 
5,7-DHT (or saline) administration with desipramine $(20 \mathrm{mg} / \mathrm{kg}$, i.p.), an inhibitor of neuronal NE reuptake (Björklund et al., 1975).

To test the effects of inhibiting apoptosis on SNL, we administered tauroursodeoxycholic acid (TUDCA: $300 \mathrm{mg} / \mathrm{kg}$, i.p.) or saline before and after surgery. TUDCA has been reported to inhibit apoptosis and to be active systemically (Rodrigues et al., 2003); systemic administration avoids the potential for damage associated with microinjections made directly into the brain parenchyma. For each group, injections were given every other day, starting $3 \mathrm{~d}$ before surgery and continuing until animals were killed.

We tested the efficacy of TUDCA as an inhibitor of apoptosis by examining its effects on dexamethasone-induced apoptosis in thymus. Two TUDCA injections $(300 \mathrm{mg} / \mathrm{kg}$, i.p.) were given: one $2 \mathrm{~d}$ before dexamethasone $(1 \mathrm{mg} / \mathrm{kg}$, i.p.) administration and one the day of dexamethasone administration. Control animals were given saline injections instead of TUDCA solution. Rats were killed one day after dexamethasone administration.

Perfusion. Rats were deeply anesthetized with a mixture of ketamine $(67.5 \mathrm{mg} / \mathrm{kg})$, xylazine $(22.5 \mathrm{mg} / \mathrm{kg})$ and acepromazine $(1 \mathrm{mg} / \mathrm{kg})$ and perfused via the ascending aorta with 180 $\mathrm{ml}$ oxygenated $\mathrm{Ca}^{2+}$-free Tyrode's solution, $\mathrm{pH} 7.2$, followed by $500 \mathrm{ml}$ of $4 \%$ formaldehyde (freshly made from paraformaldehyde) in 0.16 m phosphate buffer, $\mathrm{pH}$ 6.9. Immediately after fixation, brains were removed and stored in a $5 \%$ sucrose solution before sectioning.

Histology and immunocytochemistry. The

RVM and spinal cord were sectioned using a freezing microtome (Leica, SM2400) at a nominal thickness of $50 \mu \mathrm{m}$. The free-floating sections were washed in PBS $\left(0.8 \%\right.$, w/v, NaCl, $0.02 \% \mathrm{KCl}, 0.144 \% \mathrm{Na}_{2} \mathrm{HPO}_{4}, 0.024 \%$ $\mathrm{KH}_{2} \mathrm{PO}_{4}, \mathrm{pH}=7.4$ ) for three 5 min intervals. RVM sections were incubated overnight at $4^{\circ} \mathrm{C}$ in solutions containing one of the following antibodies: (1) mouse anti-TPH (anti-tryptophan hydroxylase) (T0678, Sigma, 1:1000), (2) mouse anti-NeuN (MAB377, Millipore, 1:500), (3) mouse anti-CD11b (MCA75GA, AbD Serotec, 1:1000), or (4) mouse anti-GFAP (GA5, \#3670, Cell Signaling Technology, 1:1000). Spinal cord sections were incubated with goat anti-5-HT (\#20079, ImmunoStar, 1:1000). Sections were then washed in PBS and incubated for $4 \mathrm{~h}$ with Cy2-conjugated donkey anti-mouse IgG or Cy3-donkey anti-goat IgG (1:500). Secondary antibodies were purchased from Jackson ImmunoResearch. The fluorescent Nissl stain ethidium bromide (30 nM, Sigma) was used to counterstain RVM tissue (Schmued et al., 1982).

To stain for apoptosis markers, $10-\mu \mathrm{m}$-thick cryostat sections were incubated with antibodies raised against activated caspase-3 (AF835, R\&D Systems), cleaved caspase-6 (Asp162, Cell Signaling Technology), or stained for terminal deoxynucleotidyl transferase-mediated dUTP-biotin nick-end labeling (TUNEL kit; Roche). For caspase staining, RVM sections were incubated overnight at $4^{\circ} \mathrm{C}$ in a solution containing rabbit anti-cleaved caspase- 6 (1:500) or mouse anti-active caspase-3 (1:500). Sections were then washed in PBS and incubated for $2 \mathrm{~h}$ with Cy3-conjugated donkey antirabbit (1:500) or Cy3-conjugated donkey anti-mouse (1:500) and the Nissl counterstain SyBr RNA II Green Gel Stain (S-7564, Invitrogen, 1:10,000). For TUNEL, sections were rinsed in $\mathrm{dH}_{2} \mathrm{O}$ and then permeabilized with Tris-buffered saline (TBS; $135 \mathrm{~mm} \mathrm{NaCl}$ and $25 \mathrm{~mm}$ Tris-HCl; $\mathrm{pH}=7.4$ ) containing $0.2 \%$ Triton X-100 and $0.2 \%$ Tween 20 for $1 \mathrm{~h}$ at room temperature. Following permeabilization, the sections were rinsed in TBS then incubated in TdT (terminal deoxynucleotidyl transferase) reaction buffer (Roche, $1600 \mathrm{U} / \mathrm{ml}$ terminal transferase, $40 \mathrm{~nm}$ biotin-16-dUTP, 200 $\mathrm{mm}$ potassium cacodylate, $5 \mathrm{~mm} \mathrm{CoCl}_{2}, 250 \mu \mathrm{g} / \mathrm{ml}$ bovine serum albumin, $25 \mathrm{~mm}$ Tris- $\mathrm{HCl} ; \mathrm{pH}$ 6.6) for $2 \mathrm{~h}$ at $37^{\circ} \mathrm{C}$. The reaction was terminated in TBS containing $20 \mathrm{~mm}$ EDTA; the sections were washed in several
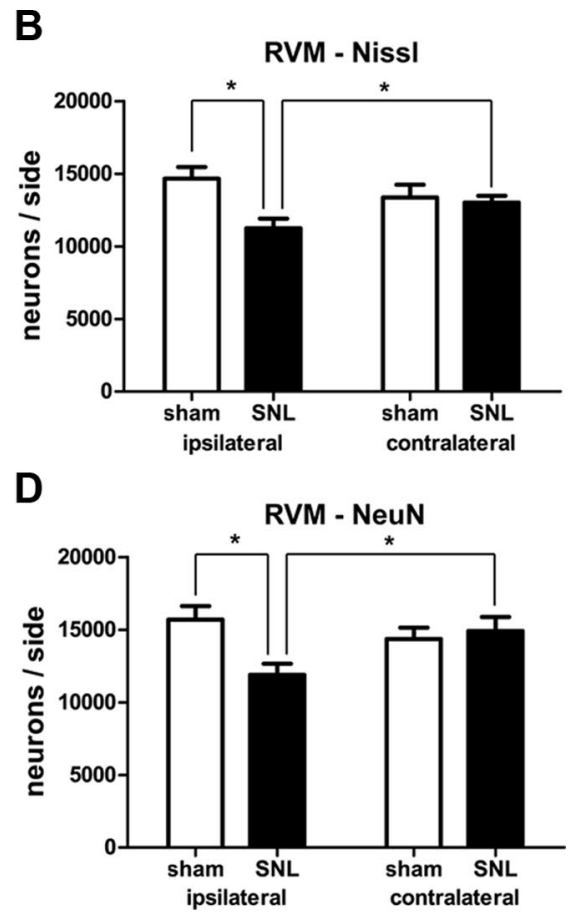

B

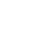

Figure 2. SNL-induced tactile hypersensitivity and neuronal loss in RVM. $\boldsymbol{A}$, Paw withdrawal thresholds, measured by von Frey

Tactile Responses

*

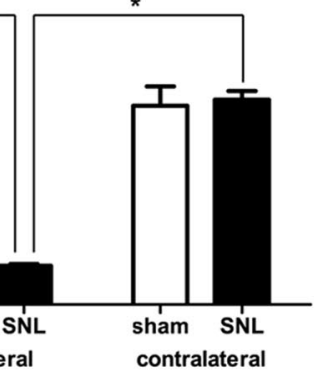

nuc. (VII) - NissI

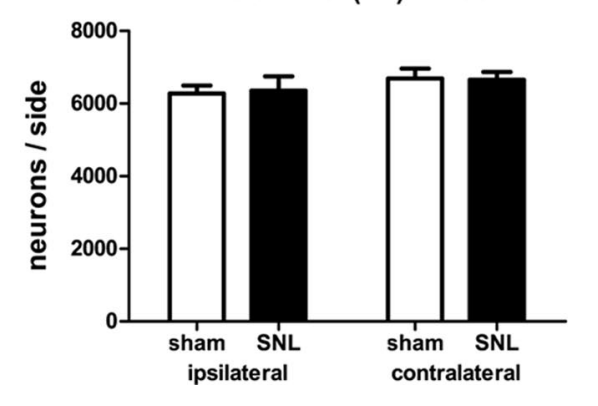

in RVM. A, Paw withdrawal thresholds, measured by von Frey
mpared with those in sham-operated rats or to those observed on the contralateral side in SNL rats ( ${ }^{*} p<0.05$; two-way ANOVA). $\boldsymbol{B}$, Significantly fewer Nissl-stained neurons were observed ipsilateral to SNL ( ${ }^{*} p<0.05$, two-way ANOVA). C, SNL resulted in no significant differences in the number of neurons in the facial nucleus ( $p>0.05$, two-way ANOVA). D, SNL resulted in a significant decrease in the number of NeuN-labeled neurons ipsilateral to the surgery $\left({ }^{*} p<0.05\right.$, two-way ANOVA).

changes of TBS and incubated in streptavidin conjugated to Cy3 (Jackson ImmunoResearch) and counterstained with SyBr RNA II Green Gel Stain (Invitrogen, 1:10,000) in TBS containing $0.2 \%$ Tween 20 and $0.2 \%$ casein for $2 \mathrm{~h}$ at room temperature.

Tissue was stained for the $\mu$-opioid receptor (MOR) after heatinduced epitope retrieval. Ten-micrometer-thick cryostat sections were exposed to a temperature of $101^{\circ} \mathrm{C}$ for $30 \mathrm{~min}$ in a $10 \mathrm{~mm}$ solution of citric acid. Tissue was then washed three times ( 5 min each) in TBS and incubated overnight at $4^{\circ} \mathrm{C}$ in guinea pig anti-MOR and mouse anti-TPH. The guinea pig anti-MOR was a generous gift from Dr. Robert Elde (University of Minnesota, Minneapolis, MN) and was characterized as specific in MOR knock-out mice (Liu et al., 2011). Tissue was washed in TBS and then incubated in Cy3-conjugated donkey anti-guinea pig IgG, Cy5-conjugated donkey anti-mouse IgG and counterstained with SYBR Green II (Invitrogen, 1:10,000) for $2 \mathrm{~h}$.

All tissue was dehydrated in graded alcohols (50-100\%) and cleared in xylene. The slides were mounted with coverslips using DPX (Fluka).

Microscopy and quantification. Conventional microscopy was used to collect images of the RVM for cell counting. An Olympus BX50 fluorescence microscope equipped with filter sets designed to allow selective visualization of $\mathrm{Cy} 2$ and $\mathrm{Cy} 3$ was used. Microscopic images were collected with a Scion 1346 digital camera. Confocal images were collected using an Olympus FluoView FV1000 microscope. ImageJ 1.29 (developed at NIH and available at http://rsb.info.nih.gov/ij/) or Photoshop was used to adjust contrast and brightness in images.

The RVM was defined as an isosceles triangle that lies at the level of the facial nucleus with a base having a width equal to that of the combined pyramidal tracts, and its height equal to half the width of the base (Fig. 1) (Gu and Wessendorf, 2007). The RVM extended from the rostral end of inferior olive to the caudal end of the trapezoid body. It was divided into ipsilateral and contralateral sides by the midline.

In Nissl-stained sections of the RVM, two distinct populations of cells were found: (1) cells with dark cytoplasm, a vacuous nucleus and a single distinct nucleolus (Fig. 1E1, arrows), and (2) cells with very lightly 
stained cytoplasm, a dark nucleus, and nuclear granulations rather than a nucleolus (Fig. 1 E1, arrowheads). The first group was classified as neurons and the second as glia. These distinct Nissl-stained populations were confirmed by immunohistochemistry (e.g., NeuN for neurons and GFAP and CD11B for astrocytes and microglia, respectively). Cell counting was based on cells' Nissl staining (including counting of TPHimmunoreactive (-IR) neurons, which were Nissl counterstained); the same sections were used for counting Nissl-stained neurons, glia and TPH-IR neurons. NeuN-IR neurons were counted in a separate population of rats and their counting was not based on Nissl-staining (see paragraph below).

The numbers of cells were estimated separately for each half of the RVM (i.e., both ipsilateral and contralateral to the surgery). Systematic random sampling and unbiased stereological methods were used for quantification as described previously (Gu and Wessendorf, 2007). Five RVM sections (each $50 \mu \mathrm{m}$ thick) per animal were sampled; the first section sampled was selected randomly. The sampling interval thereafter was determined based on the number of sections within the RVM and was usually every sixth section. For each selected section, a lowmagnification $(2 \times)$ image of the RVM was captured. A grid was randomly cast over the image (Fig. 1, line drawing) and systematic random sampling was again used when choosing the grid intersections to be evaluated (Howard and Reed, 1998; Reed and Howard, 1998). Once an intersection was chosen, a stack of images was made at $40 \times$ while focusing through the full thickness of the section (Fig. 1C,D). Cells were counted as follows. A counting frame was superimposed on the stack of images (Howard and Reed, 1998). The right boundary and the upper boundary of the counting frame were used as acceptance lines (Fig. 1C,D, dotted lines); the other two boundaries were forbidden lines (Fig. 1C,D, solid lines). Neurons were counted only if nuclei (for NeuN-labeled neurons) or nucleoli (for Nissl-stained neurons) (Popken and Farel, 1997) either fell entirely inside the counting frame or if they crossed an acceptance line without also crossing a forbidden line. NeuN-labeled neurons were counted when the top of the nucleus was found within the thickness of the tissue section. Nissl-stained neurons were counted when the nucleolus was present within the thickness of the tissue section and TPH-IR neurons were counted based on their Nissl counterstaining. To estimate the total number of neurons $(N)$ in the RVM per animal, we used the following equation: $N=(D \times V)$, where $D$ is the neuronal density of the RVM, and $V$ is the volume of the RVM. To estimate the neuronal density of the RVM in each rat, we used the following equation: $D=N(a \times t \times$ $g$ ), where $N=$ the number of neurons counted per rat, $a=2500 \mu \mathrm{m}^{2}$ (the area of the counting frame sampled), $t=50 \mu \mathrm{m}$ (the thickness of the section sampled), and $g=20$ (the number of counting frames sampled per rat). To estimate the volume of the RVM from each rat, we used the following equation: $V=\Sigma(A \times I \times t)$, where $A$ is the cross-sectional area of RVM in which the sections were sampled, $I$ is the interval between adjacent sampled sections, and $t=50 \mu \mathrm{m}$ (the thickness of section sampled).

To determine the effects of SNL on spinal 5-HT innervation, the density of 5-HT labeling was examined in the superficial dorsal horn using a $40 \times / 1.4$ numerical aperture objective. The number of 5-HT varicosities in the lateral and medial superficial dorsal horn was determined using the Finding Maxima routine of ImageJ. The density was then calculated by dividing those numbers by the corresponding cross-sectional areas of the regions being examined. The same value for noise tolerance was used in all cases.

The intensity of MOR immunoreactivity in the RVM was also determined with ImageJ. A region of interest was outlined and the mean intensity was determined using the measurement function.

Statistics. Differences among treatment groups were identified either by one-way or two-way analyses of variances (ANOVA); post hoc comparisons were made after two-way ANOVAs with a Bonferroni test. Chisquare tests were used to detect differences in proportions. $p<0.05$ was considered significant. Statistical tests were performed using the GraphPad Prism software and the statistical tools available on the GraphPad website (http://www.graphpad.com).

Von Frey testing for tactile hypersensitivity. Mechanical sensitivity was determined by measuring the paw withdrawal threshold in response to the application of von Frey filaments, using the up-down method of
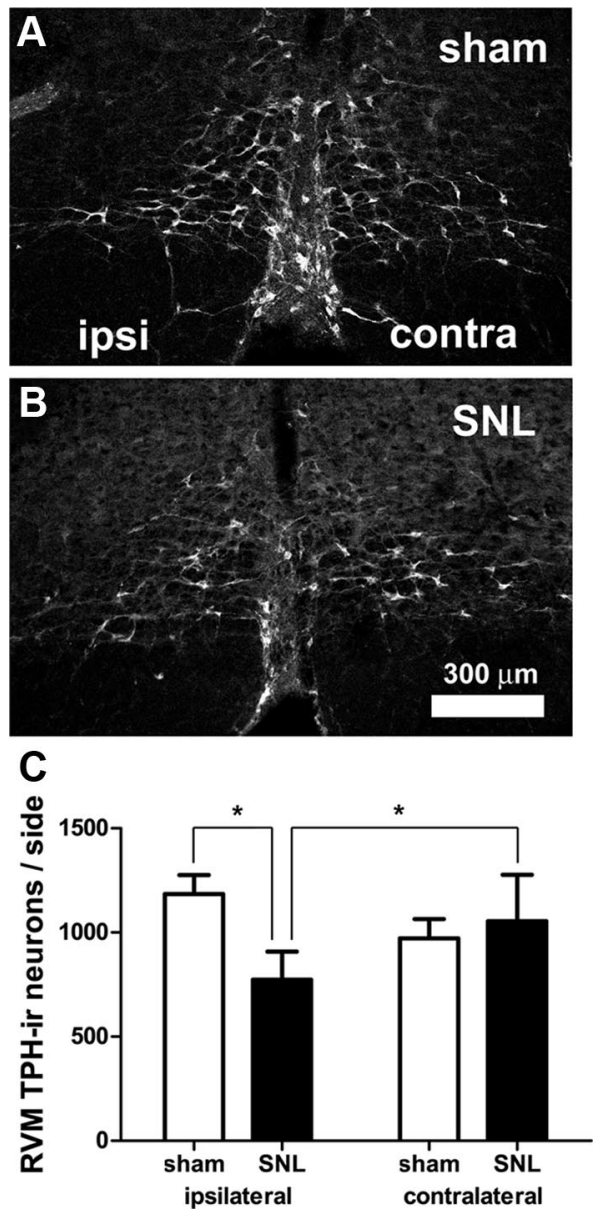

Figure 3. SNL loss of TPH-IR neurons in the RVM. $\boldsymbol{A}, \boldsymbol{B}$, Confocal images showing TPH-IR in the RVM in sham-operated $(\boldsymbol{A})$ and SNL-treated $(\boldsymbol{B})$ rats. Parameters for image acquisition and display (brightness, contrast, filtering) were identical. "Ipsilateral" and "contralateral" are relative to the nerve ligation. $\boldsymbol{C}$, The number of RVM TPH-IR neurons ipsilateral to SNL was significantly less than contralateral to SNL. In addition, the number was significantly less than that found ipsilateral to sham-surgery ( ${ }^{*} p<0.05$; two-way ANOVA). TPH-IR neurons were counted based on their Nissl counterstaining, as described in Materials and Methods. Scale bar in $\boldsymbol{B}$ applies to $\boldsymbol{A}$ and $\boldsymbol{B}$.

Chaplan (Chaplan et al., 1994). In brief, rats were placed on a wire mesh surface, covered by an inverted plastic cage and allowed to habituate for 15 min. Filaments were then applied to the plantar surface of the hindpaw. If application of the filament evoked no response, the next-larger filament was applied; if application elicited withdrawal, the next-smaller filament was applied. This sequence was repeated until the largest filament was used or until four filaments were applied after the first withdrawal was noted. Withdrawal thresholds were measured before surgery and at $2-3$ dintervals after surgery. In all cases, thresholds were measured bilaterally.

\section{Results}

SNL induced tactile hypersensitivity ipsilateral to the surgery As previously reported (Kim and Chung, 1992; Blenk et al., 1997; Ringkamp et al., 1999; Li et al., 2000), SNL resulted in hypersensitivity to tactile stimuli ipsilateral, but not contralateral, to the lesion. Ten days after surgery the withdrawal threshold for the hindpaw ipsilateral to the surgery was $2.7 \pm 0.5 \mathrm{~g}$ (mean \pm SEM) in rats receiving SNL, which was significantly lower than that in sham-operated rats $(14.0 \pm 2.7 \mathrm{~g} ; p<0.05, n=8$ animals for each group, total degrees of freedom $[\mathrm{df}]=31$ ). Thresholds in the ipsilateral paws of rats subjected to SNL were also significantly lower than those in their contralateral hindpaws $(14.5 \pm 1.3 \mathrm{~g}$; 
$p<0.05$, Fig. 2A). Paw withdrawal thresholds determined before surgery were not significantly different between experimental groups.

\section{SNL reduced the number of RVM neurons}

SNL resulted in a significant decrease in the number of RVM neurons ipsilateral to the lesion (Figs. $1 A, B, 2 B$ ). In rats that had received SNL, the number of Nisslstained neurons in the half of the RVM ipsilateral to the lesion was 11,248 \pm 668 (mean \pm SEM), which was significantly less (by 23\%) than the number found in the ipsilateral side of the RVM in shamoperated rats $(14,665 \pm 800, p<0.05, n=$ 8 animals in each group, total df $=31$ ). The number of neurons ipsilateral to SNL was also significantly less (by 14\%) than that on the contralateral side of the same animals $(p<0.05$, Fig. $2 B)$ but the number of RVM neurons on the contralateral side was not significantly different between rats receiving SNL and shamoperated rats (SNL: $13,003 \pm 471$ vs sham: $13,365 \pm 872, p>0.05$, Fig. $2 B$ ). No significant differences were observed between the volumes of the RVMs in shamoperated and experimental rats (sham ipsilateral $=1.123 \pm 0.050 \mathrm{~mm}^{3}$; sham contralateral $=1.131 \pm 0.057 \mathrm{~mm}^{3} ; \mathrm{SNL}$ ipsilateral $=1.075 \pm 0.079 \mathrm{~mm}^{3} ;$ SNL contralateral $=1.077 \pm$ $0.083 \mathrm{~mm}^{3}, p>0.05, n=8$ animals, in each group, total $\mathrm{df}=31$ ).

The loss of neurons after SNL was not nonspecific. The number of neurons in the facial nucleus, which is adjacent to the RVM but not involved in pain modulation, was unchanged (ipsilateral sham: $6267 \pm 219$; ipsilateral SNL $6204 \pm 422$; contralateral sham: $6693 \pm 270$; contralateral SNL: $6542 \pm 187: p>0.05, n=$ 8 animals in each group, total $\mathrm{df}=31$, Fig. $2 C$ ). This suggests that cell loss in the RVM was not due to any indiscriminant brainstem pathology resulting from SNL.

To confirm that SNL did not simply transform RVM neurons to cells with a glia-like morphology, we repeated the experiment in a second group of animals, staining sections for the neuronal marker NeuN (Mullen et al., 1992). SNL resulted in a significant decrease in the number of RVM NeuN-IR neurons ipsilateral to the lesion. In rats subjected to SNL, the number of NeuN-IR neurons in the half of the RVM ipsilateral to the lesion was $11,898 \pm 768$, which was significantly less $(24 \%)$ than the number found in the ipsilateral side of sham-operated rats $(15,688 \pm$ 945, $p<0.05, n=8$ animals in each group, total $\mathrm{df}=31$, Fig. $2 D)$. The number of NeuN-IR neurons ipsilateral to SNL was also significantly less (by 20\%) than that on the contralateral sides of the same animals $(14,913 \pm 964, p<0.05$, Fig. $2 D)$. Thus, the NeuN results validated those obtained using Nissl staining and the latter method was used as the basis of neuronal counting for the remainder of these experiments.

RVM TPH-IR neurons were decreased in rats receiving SNL $\mathrm{TPH}$, the rate-limiting enzyme in 5-HT synthesis, was used as a marker for 5-HT neurons in the RVM. In both rats receiving SNL and sham-operated rats, TPH-IR neurons were found through-

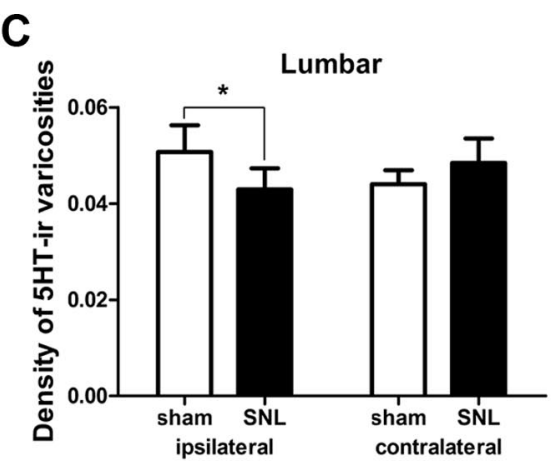

D

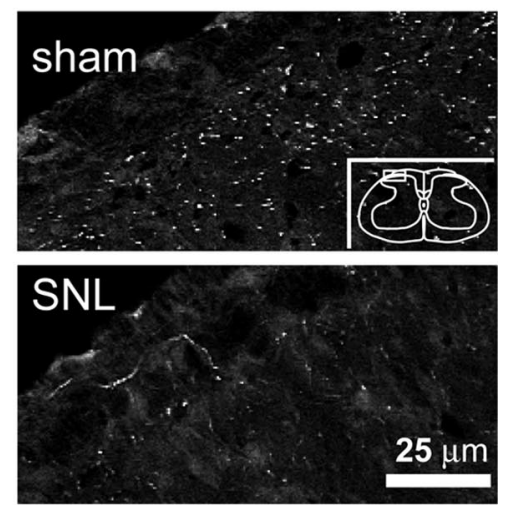

Thoracic

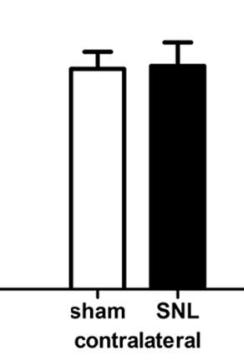

$25 \mu \mathrm{m}$

Figure 4. Effect of SNL on 5-HT immunoreactivity (5-HT-ir) in the superficial dorsal horn of the spinal cord. A-C, SNL signifisegment $L 4\left({ }^{*} p<0.05\right.$; two-way ANOVA). $\boldsymbol{D}$, Images of 5 -HT immunoreactivity in superficial dorsal horn of rats receiving sham surgery or SNL. Note reduced 5-HT immunoreactivity in SNL image. Box in inset denotes area from which images were obtained.

out the RVM. However, the number of RVM TPH-IR neurons ipsilateral to SNL was significantly less (by 35\%) than the number of TPH-IR neurons ipsilateral to sham surgery (SNL ipsilateral: $773 \pm 134$ vs sham ipsilateral: $1184 \pm 92, p<0.05, n=8$ animals in each group, total $\mathrm{df}=31$, Fig. 3 ). Within SNL animals, the number of TPH-IR neurons ipsilateral to the lesion was also significantly less $(27 \%)$ than the number contralateral to the lesion (SNL contralateral: $1055 \pm 222 p<0.05$, Fig. $3 C$ ). The proportion of 5-HT cells lost (35\%) was significantly larger than the percentage decrease observed among all RVM neurons (23\%), suggesting that 5 -HT neurons are more sensitive to the effects of peripheral nerve damage than RVM neurons as a whole $(p<$ $0.0001 ; \chi^{2}$ with Yates correction).

\section{Fewer 5-HT-IR varicosities found in substantia gelatinosa ipsilateral to $\mathrm{SNL}$}

Since RVM 5-HT neurons project to dorsal spinal cord (Bowker et al., 1981; Skagerberg and Björklund, 1985; Kwiat and Basbaum, 1992; Kalyuzhny et al., 1996), we examined whether spinal 5-HT immunoreactivity decreased after SNL (Fig. 4). At spinal levels C2, T2 and L4, the density of 5-HT-IR varicosities in the ipsilateral superficial dorsal horn was significantly lower in rats receiving SNL than in sham-operated rats. At the cervical level, the density of 5-HT varicosities in rats treated with SNL was $0.033 \pm 0.002$ varicosities $/ \mu \mathrm{m}^{2}$ on the ipsilateral side (where 1 $\mu \mathrm{m}^{2}=10^{-12} \mathrm{~m}^{2}$ ), which was significantly lower (by 30\%) than in sham-operated rats $\left(0.047 \pm 0.004 / \mu \mathrm{m}^{2}, p<0.05, n=6\right.$ animals receiving SNL, $n=8$ sham-operated animals, total $\mathrm{df}=$ 27, Fig. $4 A$ ). Densities in animals treated with SNL at the thoracic and lumbar levels $\left(0.039 \pm 0.005 / \mu \mathrm{m}^{2}\right.$ and $0.043 \pm 0.004 / \mu \mathrm{m}^{2}$, 


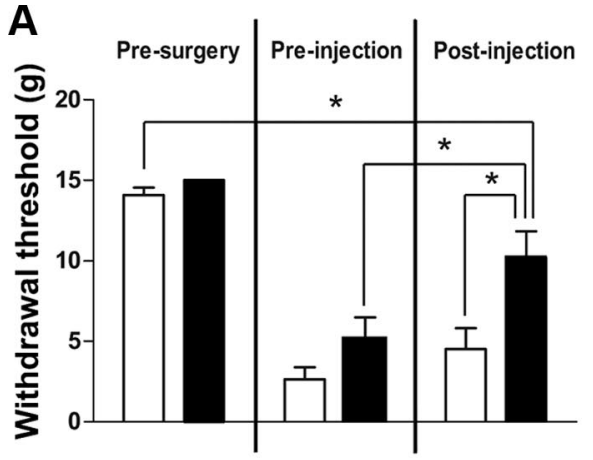

SNL: Effect of 5,7-DHT
B

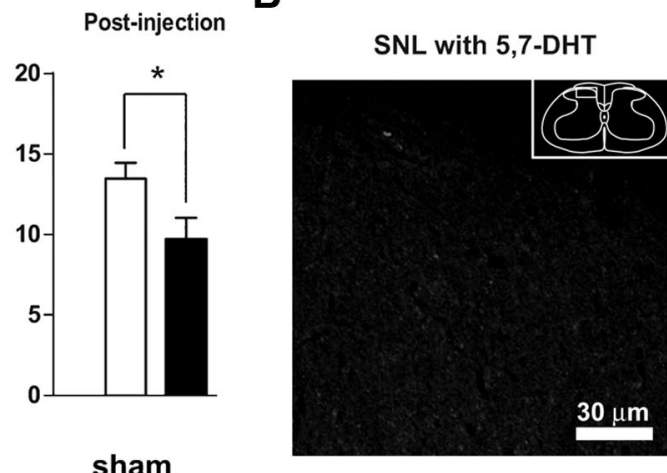

vehicle treated group

5,7-DHT treated group

Figure 5. Intracisternal injection of the serotonin neurotoxin 5,7-DHT partially reversed mechanical hypersensitivity after SNL. A, Withdrawal thresholds became significantly higher after rats receiving SNL were injected with 5,7-DHT. Also, thresholds were significantly higher in rats receiving SNL that were treated with 5,7-DHT than in rats receiving SNL that were given saline $\left({ }^{*} p<0.05\right.$; two-way ANOVA). B, Image of 5-HT immunoreactivity in superficial dorsal horn of a rat that had received SNL and that was treated with 5,7-DHT (compare to Fig. 4D). Note lack of 5-HT immunoreactivity. Box in inset denotes area from which image was obtained.


Figure 6. TUDCA inhibited dexamethasone-induced apoptosis in thymus. $A$, Dexamethasone $(1 \mathrm{mg} / \mathrm{kg})$ increased staining for activated caspase-3 in thymus. $\boldsymbol{B}$, Treatment with TUDCA decreased caspase-3 immunoreactivity in dexamethasone-treated rats. C, TUDCA administration alone did not cause increased caspase-3 staining. $\boldsymbol{D}$, Thymus tissue from naive rats showed little apoptosis.

respectively) were also significantly lower on the ipsilateral side (decreases of $22 \%$ and $15 \%$, respectively) than those in shamoperated rats (Fig. $4 B, C$ ). There were no significant differences on the contralateral sides of the superficial dorsal horn at any spinal level.

\section{Depletion of 5-HT reversed mechanical hypersensitivity after SNL}

To determine whether loss of the RVM 5-HT neurons remaining after SNL would further exacerbate cutaneous hypersensitivity, we used intracisternal injection of the serotonin neurotoxin 5,7DHT to deplete 5-HT in rats that had undergone SNL (Fig. 5). Rather than being lower, mechanical withdrawal thresholds were significantly higher after 5,7-DHT $(5.2 \pm 1.3 \mathrm{~g}$ before injection vs $10.2 \pm 1.7 \mathrm{~g}$ after injection; $p<0.05, n=10$ animals in each group, total $\mathrm{df}=39$, Fig. $5 A$ ). These thresholds were also significantly higher than those in rats that had received SNL and that were subsequently treated with saline rather than 5,7-DHT (10.2 $\pm 1.7 \mathrm{~g}$ vs $4.5 \pm 1.3 \mathrm{~g}$, respectively; $p<0.05)$. Treatment with 5,7-DHT markedly reduced 5-HT immunoreactivity in the spinal cord (Fig. 5B).
Administration of TUDCA reduced both the loss of RVM neurons and cutaneous hypersensitivity after SNL Previous studies have reported that neuronal apoptosis occurs in the spinal cord and cerebral cortex after nerve injury and that inhibiting caspases reduces cell loss (Coggeshall et al., 2001; Whiteside and Munglani, 2001; Moore et al., 2002; Scholz et al., 2005; Siniscalco et al., 2007; Fuccio et al., 2009). To test whether apoptosis might mediate the cell loss we observed in the RVM, we administered an apoptosis inhibitor; to avoid the local damage that could result from a direct microinjection of a caspase inhibitor into the RVM, we gave rats a long-acting inhibitor of apoptosis that can be administered systemically. Ursodeoxycholic acid (UDCA) is a bile acid used for treating hepatic disease (Ward et al., 1984) that has been reported to inhibit apoptosis (for review, see Rodrigues and Steer, 2001; Solá et al., 2007) and that acts at least in part by inhibiting the translocation of Bax from the cytosol to the mitochondrion (Rodrigues et al., 1998). UDCA also activates cell survival pathways (Solá et al., 2007). The taurine conjugate of UDCA (TUDCA) has similarly been reported to inhibit apoptosis (Rodrigues et al., 2003; Ramalho et al., 2008) and promote cell survival (Schoemaker et al., 2004), but has greater solubility in water. For this reason, TUDCA was used in these experiments.

We first tested the actions of TUDCA by examining its effects on apoptosis in the thymus. We induced apoptosis in the thymus by treatment with $1 \mathrm{mg} / \mathrm{kg}$ dexamethasone, an immunosuppressant glucocorticoid (Compton et al., 1987; Quaglino and Ronchetti, 2001), which greatly enhanced staining for caspase-3. However, in rats treated with both TUDCA and dexamethasone, we found a marked decrease in caspase-3 labeling compared with treatment with dexamethasone alone (Fig. 6).

In the brainstem, we found that administration of TUDCA prevented loss of RVM neurons after SNL (Fig. 7). In rats receiving SNL and treated with TUDCA, the number of RVM neurons ipsilateral to the lesion was $17,976 \pm 1202$, which was signifi- 
A


Figure 7. TUDCA prevented neuronal loss after SNL, including serotonergic cell loss, and partially reversed SNL-induced mechanical hypersensitivity. $A$, Compared with vehicle-treated rats, TUDCA-treated rats had significantly more Nissl-stained neurons ipsilateral to SNL $\left({ }^{*} p<\right.$ 0.05, two-way ANOVA). B, TUDCA-treated rats also had significantly more TPH-IR neurons after SNL ( ${ }^{*} p<0.05$, two-way ANOVA). In contrast to saline-treated rats, there were no significant differences between the numbers of RVM neurons ipsilateral and contralateral to SNL in TUDCAtreated animals. C, Beginning $4 \mathrm{~d}$ post-SNL, the withdrawal thresholds of the ipsilateral hindpaws of TUDCA-treated rats were significantly higher than those in animals treated with saline $(p<0.05$; two-way ANOVA). There were no significant differences between the withdrawal thresholds of the contralateral hindpaws at any time point. Inverted triangles, Contralateral saline; squares, contralateral TUDCA; circles, ipsilateral TUDCA; triangles, ipsilateral saline.

cantly higher (by 43\%) than the number found in the ipsilateral sides of vehicle-treated rats that had received SNL $(12,540 \pm 930$; $p<0.05, n=8$ animals in each group, total $\mathrm{df}=31$, Fig. $7 A)$. As expected, in vehicle-treated rats, the number of RVM neurons in the ipsilateral side $(12,540 \pm 929)$ was significantly less (by 26\%) than the number found in the contralateral side $(16,949 \pm 1074$, $p<0.05$, Fig. $7 A)$. There was no significant difference between the number of neurons in the ipsilateral and contralateral sides of TUDCA-treated rats receiving SNL (TUDCA ipsi: 17,976 \pm 1202, TUDCA contra: $16,675 \pm 828$, Fig. $7 A$ ), nor between the numbers of neurons found in the contralateral sides of the two treatment groups (SNL with TUDCA: 16,675 \pm 828 , SNL with saline: $16,949 \pm 1074, p>0.05$, Fig. $7 A$ ).

TUDCA also prevented the loss of 5-HT neurons in the RVM. The number of RVM 5-HT neurons ipsilateral to SNL in TUDCA-treated animals ( $1353 \pm 96)$ was significantly higher (by $30 \%)$ than the number in vehicle-treated rats $(1043 \pm 118, p<$ $0.05, n=8$ animals in each group, total $\mathrm{df}=31$, Fig. $7 B$ ). Again, as expected, the number of 5-HT-IR RVM neurons in the ipsilateral side of vehicle-treated rats $(1043 \pm 118)$ was significantly less (by $27 \%$ ) than that in the contralateral side $(1427 \pm 211, p<$ 0.05, Fig. $7 B$ ). In TUDCA-treated rats receiving SNL, there was no significant difference between the number of neurons in the ipsilateral and contralateral sides (TUDCA ipsi: $1353 \pm 96$, TUDCA contra: $1251 \pm 99, p>0.05$, Fig. $7 B$ ). Despite the efficacy of TUDCA, though, we found neither caspase- 3 labeling, caspase-6 labeling nor TUNEL in the RVM after SNL.

TUDCA administration also reduced SNL-induced mechanical hypersensitivity. Beginning at day 4 post-SNL, the withdrawal thresholds of the ipsilateral hindpaws of TUDCA-treated rats (day 4: $3.5 \pm 0.5 \mathrm{~g}$; day $6: 4.0 \pm 0.5 \mathrm{~g}$; day $8: 4.6 \pm 1.1 \mathrm{~g}$; day $10: 5.2 \pm 1.3 \mathrm{~g}$ ) were significantly higher than those animals treated with vehicle (day 4: $1.1 \pm 0.3$ g; day 6: $1.3 \pm 0.2$ g; day 8: $1.2 \pm 0.3$ g; day 10: $1.2 \pm 0.2$ g; $p<0.05, n=10$ animals treated with TUDCA, $n=9$ animals treated with vehicle, $\mathrm{df}$ interaction $=7, \mathrm{df}$ treatment $=1, \mathrm{df}$ time $=7, \mathrm{df}$ subjects $=17, \mathrm{df}$ residual $=119$, total $\mathrm{df}=151$, Fig. $7 C$ ).

\section{Glia: activation and increased numbers after SNL}

RVM glial activation appears to have a role in descending facilitation of nociception in a model of persistent pain (Wei et al., 2008). To determine whether glial activation might be responsible for the neuronal loss, we stained for markers of astrocytes (GFAP) and microglia (CD11B) in RVM after SNL. At day 3, we found a bilateral increase in activation of astrocytes in animals receiving SNL compared with sham-operated animals (Fig. $8 \mathrm{~A}-$ $D$ ); GFAP staining was decreased by day 10 . Conversely, although little labeling was observed at day 3 , we found markedly stronger labeling for $\mathrm{CD} 11 \mathrm{~B}$ at day 10 in rats receiving SNL. Again, the labeling increased both ipsilateral and contralateral to SNL (Fig. $8 E-H)$. Using Nissl-stained tissue, we also found a significant bilateral increase in numbers of glia in the RVM of SNL-treated animals compared with sham-operated animals (SNL ipsi: $87,277 \pm 10,354$ vs sham ipsi: $60,430 \pm 7551$ or $44 \%$ higher, SNL contra: $85,903 \pm 9091$ vs sham contra: $56,104 \pm 7912$ or $52 \%$ higher; $p<0.05, n=5$ animals in each group, total $\mathrm{df}=19$, Fig. $8 I$ ). To determine whether this increase in glial activation and number was nonselective and found across the brainstem, we examined the adjacent facial nucleus. In that nucleus we found no significant increase in the number Nissl-stained glia (Fig. $8 \mathrm{~J}$ ) or in the activation of glia in SNL-treated rats, compared with shamoperated rats. Treatment with TUDCA significantly reduced the increase in RVM glia observed after SNL (TUDCA ipsi: 62,306 \pm 3736 vs vehicle ipsi: $85,541 \pm 2972$, or $27 \%$ fewer; TUDCA contra: $60,437 \pm 4315$ vs vehicle contra: $80,086 \pm 2899$, or $25 \%$ fewer; $p<0.05$ in both cases, $n=7$ animals treated with TUDCA, $n=6$ animals treated with vehicle, total $\mathrm{df}=25$ ), suggesting that the increase in glia was in response to cell death.

\section{MOR expression in RVM after SNL}

Previous studies have suggested that RVM neurons expressing the $\mu$-opioid receptor (MOR) mediate descending facilitation of nociception after SNL (Porreca et al., 2001). Although RVM neurons were lost after SNL (see Results, above), MOR immunoreactivity in the RVM appeared to be unchanged (Fig. 9A,B). When the intensity 


\section{ipsilateral RVM}
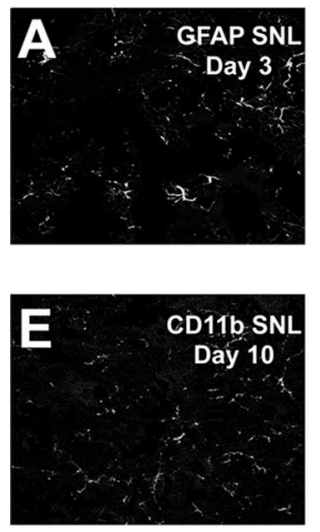

I
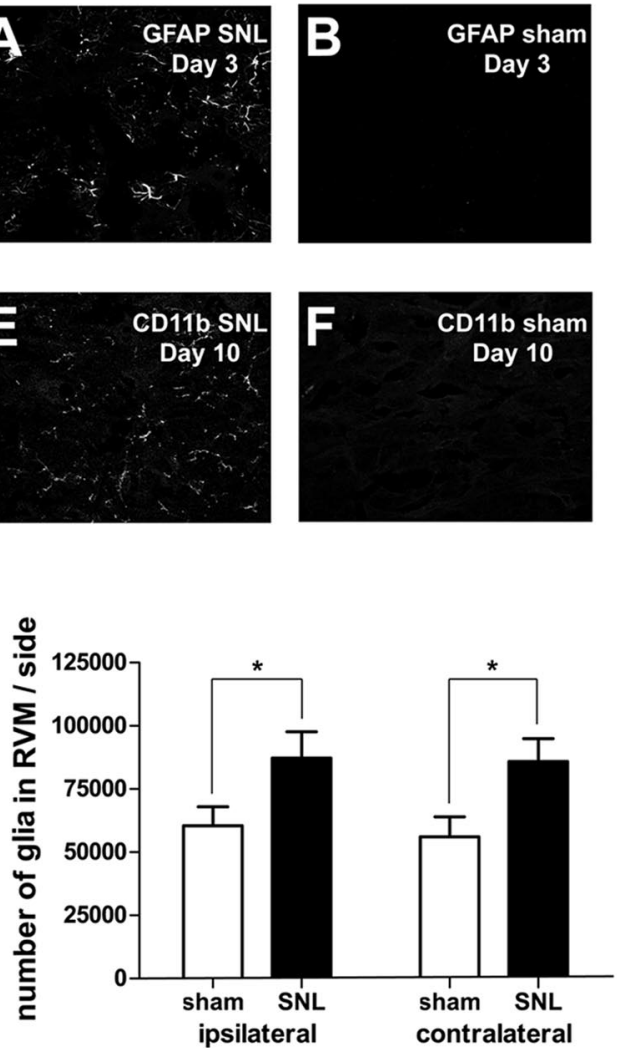

contralateral RVM
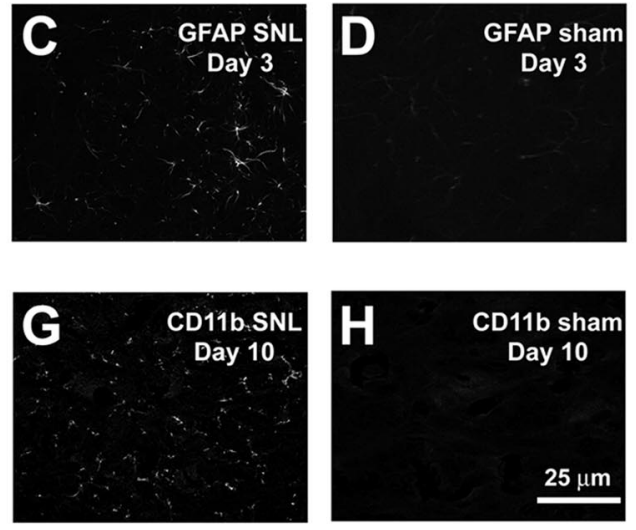

$\mathbf{J}$

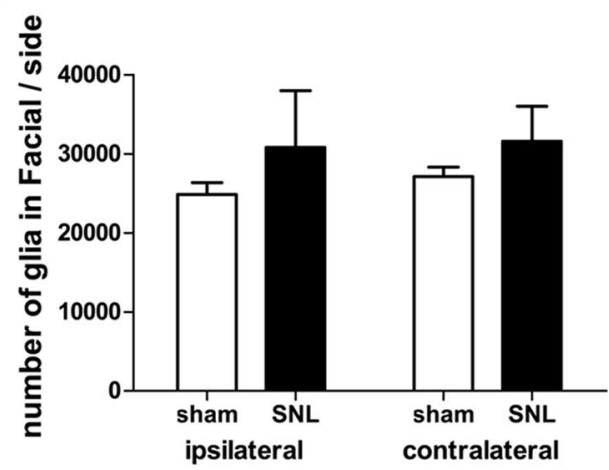

Figure 8. SNL induced a bilateral activation of astrocytes and microglia and an increase in glial number. $\boldsymbol{A}-\boldsymbol{D}$, At day 3 , astrocytes were activated (as shown by increased GFAP labeling) in the ipsilateral and contralateral RVM after SNL, compared with sham. $\boldsymbol{E}-\boldsymbol{H}$, At day 10 , microglia were activated after SNL compared with sham, as shown by increased labeling for the microglial marker, CD11b. I, We observed significantly more Nissl-stained glia in the RVM after SNL and the increase was bilateral.J, No significant increases in glial number were found in Facial nucleus after SNL. Scale bar in $\boldsymbol{H}$ applies to $\boldsymbol{A}-\boldsymbol{H}$.
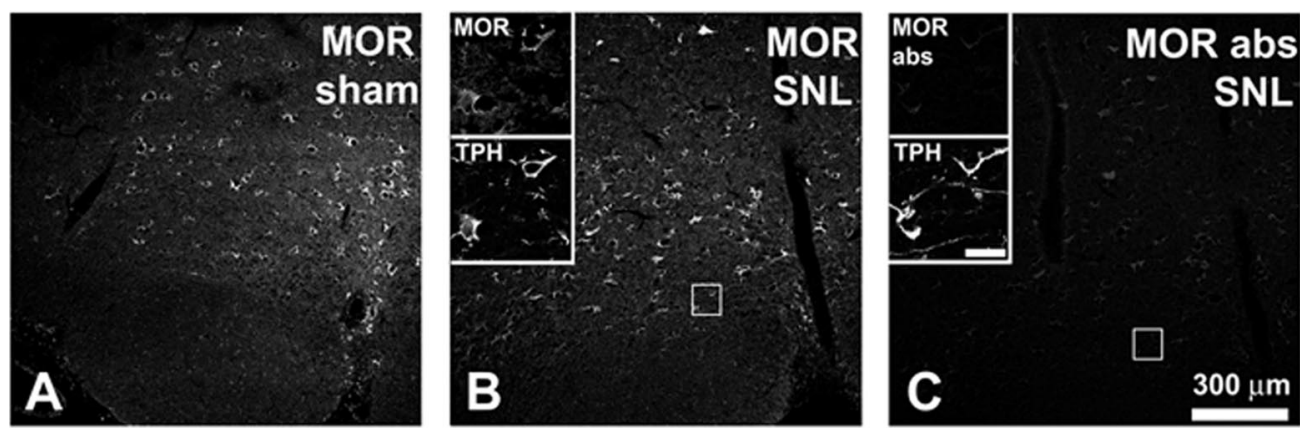

Figure 9. MOR-immunoreactivity in the RVM appears to be unchanged after SNL. A, MOR immunoreactivity in RVM ipsilateral to sham surgery. $\boldsymbol{B}$, MOR immunoreactivity in RVM ipsilateral to SNL. RVM neurons, including TPH-IRneurons expressed MOR immunoreactivity after SNL. Section was double-stained; insets show expression of MOR immunoreactivity by TPH-IR RVMneurons. Insets were taken from the region outlined by the square. $\boldsymbol{C}$, Absorption control. Section of RVM serially adjacent to that in $\boldsymbol{B}$; note marked reduction in labeling. Section was also double-stained and the same TPH-IRneurons visible in B can be seen in the insets. Again, the square indicates the region from which the insets were taken. Scale bar in insets, $30 \mu \mathrm{m}$. The $300 \mu \mathrm{m}$ scale bar in Capplies to $\mathbf{A}-\mathbf{C}$.

of MOR staining was measured there was no significant difference between sham animals (55.5 \pm 2.6 arbitrary intensity units) and animals receiving SNL (53.7 \pm 3.2 arbitrary intensity units; $n=3$ animals in each group, $t$ test, $\mathrm{df}=4, p>0.05$ ). MOR immunoreactivity after SNL was observed in TPH-IR neurons as well as in neurons that were not immunoreactive for TPH (Fig. 9B).

\section{Discussion}

Nerve injury and disease can trigger a range of responses in both the peripheral and CNSs that contribute to chronic neuropathic pain (Devor, 2006). In the periphery, injured primary sensory neurons develop hyperexcitability and abnormal impulse generation (Blumberg and Jänig, 1984; Devor, 2006). Other pathophysiological changes observed in injured primary sensory neurons include the altered regulation and expression of certain molecules (e.g., neuropeptides, ion channels, enzymes, etc.) (Hokfelt et al., 2006). Increased spinal cord excitability ipsilateral to the injury (i.e., central sensitization) also appears to contribute crucially to abnormal pain conditions after tissue injury (Ji et al., 2003). NMDA receptor activation is one of the principal mechanisms in central sensitization, and its role in neuropathic pain is implied by preclinical studies showing that NMDA receptor an- 
tagonists are effective in alleviating experimental neuropathic pain (Wei and Pertovaara, 1999; Woolf and Salter, 2000; Hokfelt et al., 2006).

Pathophysiological changes in the RVM also contribute to neuropathic pain. Microinjection of a NMDA receptor antagonist before SNL (Wei and Pertovaara, 1999), and microinjection of lidocaine in the RVM after SNL have both been shown to reduce allodynia (Pertovaara et al., 1996), suggesting that activation of (and activity in) the RVM contributes to cutaneous hypersensitivity. Consistent with this idea, lesioning the DLF, in which RVM axons descend to the spinal cord, has also been reported to reverse both thermal hyperalgesia and allodynia after SNL (Ossipov et al., 2000). In addition, selective ablation of MOR-expressing RVM neurons has been reported to prevent SNL-induced experimental hypersensitivity (Porreca et al., 2001). However, neither DLF lesions nor microinjection of lidocaine into the RVM reduced cutaneous hypersensitivity within $3 \mathrm{~d}$ after SNL-they did so only $4-6$ or more days after SNL (Burgess et al., 2002). Based on these and similar findings, it has been proposed that physiological changes in the RVM contribute to the maintenance of neuropathic pain but not to its initiation.

\section{Fewer RVM neurons after SNL}

In our present studies, it was found that the number of RVM neurons ipsilateral to SNL was significantly decreased compared with sham-operated rats. Several prior studies have shown that neurons at the spinal level undergo apoptosis ipsilateral to peripheral nerve injury (Sugimoto et al., 1990; Whiteside and Munglani, 2001; Scholz et al., 2005) and apoptosis has been reported in cortex in response to nerve injury (Fuccio et al., 2009). Apoptosis would be expected to result in cell loss, although to date the loss of neurons in those regions has been controversial (Polgár et al., 2004, 2005).

Our finding of neuronal loss in the RVM suggests that death of pain modulatory neurons contributes to the pathophysiology of neuropathic pain. Although it is possible that both pro- and antinociceptive neurons are lost after SNL, the most parsimonious interpretation of our findings is that SNL selectively kills antinociceptive RVM neurons, thereby facilitating cutaneous hypersensitivity (Fig. 10).

Treatment with TUDCA blocked RVM cell loss and significantly decreased tactile hypersensitivity four or more days after SNL but did not reduce hypersensitivity 1-3 d after SNL (Fig. 7). Thus our findings suggest that cell loss underlies the RVM's contribution to the maintenance phase of neuropathic pain (see above). Glial activation in the RVM may also contribute to cutaneous hypersensitivity (Wei et al., 2008), although since we found that it occurs bilaterally it would not by itself explain the unilateral decrease in withdrawal thresholds; instead, glial activation may be an important factor in the initiation of neuropathic pain (Mei et al., 2011). In our studies, we also found that the number of glia increased after SNL. This increase was blocked by TUDCA, suggesting it may represent gliosis in response to RVM neuronal death.

Although a significant number of 5-HT neurons were lost after SNL (see Results, above), most cells that were lost (88\%) did not express 5-HT. The identity of these neurons is not known but it has been proposed that the antinociceptive neurons of the RVM are physiologically characterized as OFF-cells (Fields et al., 1983a,b, 1991; Heinricher et al., 1989). Many OFF-cells project to the dorsal horn (Fields et al., 1995) and express GABA (Winkler et al., 2006). Previous studies have suggested that changes in ONcell and OFF-cell firing drive the hypersensitivity observed in

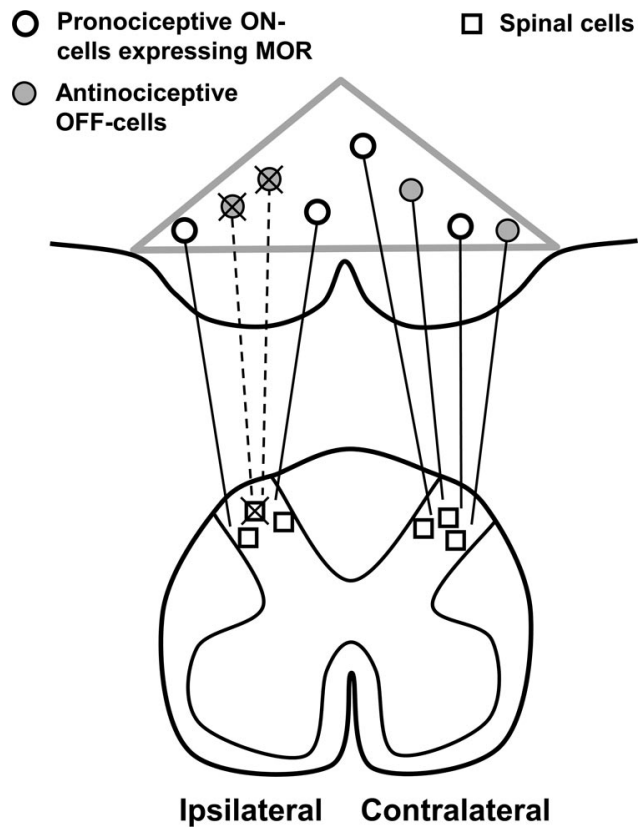

Figure 10. Summary diagram. The loss of antinociceptive neurons underlies, in part, the hypersensitivity observed in neuropathic pain. Gray triangle indicates the borders of the RVM. We propose that after SNL, antinociceptive RVM neurons (filled circles) retrogradely degenerate after apoptosis of intrinsic spinal cells (squares) and primary afferent fibers. The resulting loss of descending inhibitory tone contributes to cutaneous hypersensitivity.

SNL (Carlson et al., 2007; Gonçalves et al., 2007), but it has not yet been determined whether or not the number of OFF-cells changes. It has also been reported that neuropathic pain is maintained by RVM neurons expressing MOR (Porreca et al., 2001; Burgess et al., 2002). Consistent with this finding, MOR immunoreactivity appeared not to decrease after SNL and RVM neurons (including 5-HT neurons) expressing MOR were still observed after SNL.

\section{Mechanism of cell loss}

The cause of RVM cell loss is unclear. It has been reported that hypersensitivity after SNL could be blocked by a single microinjection of an NMDA antagonist into the RVM (Wei and Pertovaara, 1999), suggesting that excessive activity among glutamatergic afferents immediately after injury might be sufficient to kill RVM neurons. Although NMDA receptor activation may contribute to cell loss, it is unclear how activation only of ipsilateral glutamatergic afferents could be evoked physiologically. Similarly, although RVM glial activation might contribute to cell loss, it appears unlikely to be the sole cause since activation was observed bilaterally. An alternative explanation is that loss of RVM neurons arises from their spinal projections. RVM neurons project predominantly ipsilaterally to the spinal cord dorsal horn (Skagerberg and Björklund, 1985) and nerve damage or primary afferent activity have been reported to result in cell loss or apoptosis in the dorsal horn and in dorsal root ganglia (Coggeshall et al., 2001; Whiteside and Munglani, 2001; Maione et al., 2002; de Novellis et al., 2004; Polgár et al., 2005; Scholz et al., 2005; Hassanzadeh and Ahmadiani, 2006; Jalalvand et al., 2008; Sekiguchi et al., 2009; Meisner et al., 2010). Thus we propose that apoptosis of spinal cells (either neurons, glia or primary afferent fibers) in the terminal fields of bulbospinal neurons triggers retrograde degeneration of RVM neurons. 
TUDCA administration blocked RVM cell loss. TUDCA reportedly inhibits apoptosis and has been shown to have beneficial effects in in vivo and in vitro models of neurological damage that result in apoptosis, including hemorrhagic and ischemic stroke (Rodrigues et al., 2002, 2003). However, to date we have been unable to demonstrate caspase- 3 , caspase- 6 or TUNEL in the RVM after SNL, and in a study of another model of neuropathic pain, chronic constriction injury, apoptosis was not observed in the RVM (Wei et al., 2008). Thus, since TUDCA was given systemically, we conclude that it may have acted indirectly (i.e., on spinal cord or dorsal root ganglia: see paragraph above) rather than directly on the RVM. Nevertheless, apoptotic events are brief (Kerr et al., 1972; Bursch et al., 1990; Sanchez et al., 1992), which can result in few or no apoptotic cells being detected (Lawen, 2003). Moreover, TUDCA also promotes cell survival by other means than inhibiting apoptosis (Schoemaker et al., 2004) and it is possible that RVM neurons are lost via some mechanism other than the classical apoptotic pathway. Thus it remains possible that TUDCA blocks RVM cell loss by acting directly on RVM neurons.

\section{Pain facilitation by 5 -HT}

In the present study, $\sim 8 \%$ of RVM neurons were found to be serotonergic (i.e., they expressed TPH immunoreactivity). Of these, one-third were lost ipsilateral to SNL. The remaining 5-HT neurons appeared to facilitate nociception: administration of 5,7DHT, a serotonin neurotoxin, significantly improved (i.e., increased) withdrawal thresholds after SNL. This facilitatory effect might either be direct (e.g., via 5-HT3 receptors; Suzuki et al., 2005) or indirect (e.g., via gating the facilitatory or inhibitory output of the RVM). Since 5,7-DHT was given intracisternally, this finding could be due at least in part to 5,7-DHT acting on 5-HT neurons outside the RVM. However, previous studies have suggested that bulbospinal 5-HT neurons do contribute to persistent pain (McCleane et al., 2003; Suzuki et al., 2004; Rahman et al., 2006; Dogrul et al., 2009; Wei et al., 2010) and our findings are consistent with there being a role for 5-HT in maintaining neuropathic pain.

In summary, our data indicate that almost one-fourth of RVM neurons are lost after SNL, and that preventing this loss reduces the hypersensitivity observed after SNL. We propose that death of antinociceptive neurons in the RVM is responsible, at least in part, for maintaining tactile hypersensitivity after nerve damage and that changes in the RVM and the spinal cord together contribute to the phenomenon of neuropathic pain. Reducing RVM neuronal death and the associated hypersensitivity with antiapoptotic drugs may prove useful for preventing neuropathic pain in humans.

\section{References}

Amir R, Devor M (2000) Functional cross-excitation between afferent Aand C-neurons in dorsal root ganglia. Neuroscience 95:189-195.

Björklund A, Baumgarten HG, Rensch A (1975) 5,7-Dihydroxytryptamine: improvement of its selectivity for serotonin neurons in the CNS by pretreatment with desipramine. J Neurochem 24:833-835.

Blenk KH, Häbler HJ, Jänig W (1997) Neomycin and gadolinium applied to an L5 spinal nerve lesion prevent mechanical allodynia-like behaviour in rats. Pain 70:155-165.

Blumberg H, Jänig W (1984) Discharge pattern of afferent fibers from a neuroma. Pain 20:335-353.

Bowker RM, Westlund KN, Coulter JD (1981) Origins of serotonergic projections to the spinal cord in rat: an immunocytochemical-retrograde transport study. Brain Res 226:187-199.

Burgess SE, Gardell LR, Ossipov MH, Malan TP Jr, Vanderah TW, Lai J, Porreca F (2002) Time-dependent descending facilitation from the ros- tral ventromedial medulla maintains, but does not initiate, neuropathic pain. J Neurosci 22:5129-5136.

Bursch W, Paffe S, Putz B, Barthel G, Schulte-Hermann R (1990) Determination of the length of the histological stages of apoptosis in normal liver and in altered hepatic foci of rats. Carcinogenesis 11:847-853.

Carlson JD, Maire JJ, Martenson ME, Heinricher MM (2007) Sensitization of pain-modulating neurons in the rostral ventromedial medulla after peripheral nerve injury. J Neurosci 27:13222-13231.

Chaplan SR, Bach FW, Pogrel JW, Chung JM, Yaksh TL (1994) Quantitative assessment of tactile allodynia in the rat paw. J Neurosci Methods 53:55-63.

Coggeshall RE, Lekan HA, White FA, WoolfCJ (2001) A-fiber sensory input induces neuronal cell death in the dorsal horn of the adult rat spinal cord. J Comp Neurol 435:276-282.

Compton MM, Caron LA, Cidlowski JA (1987) Glucocorticoid action on the immune system. J Steroid Biochem 27:201-208.

de Novellis V, Siniscalco D, Galderisi U, Fuccio C, Nolano M, Santoro L, Cascino A, Roth KA, Rossi F, Maione S (2004) Blockade of glutamate mGlu5 receptors in a rat model of neuropathic pain prevents early overexpression of pro-apoptotic genes and morphological changes in dorsal horn lamina II. Neuropharmacology 46:468-479.

Devor M (2006) Responses of nerves to injury in relation to neuropathic pain. In: Wall and Melzack's textbook of pain (McMahon S, Koltzenburg M, eds), pp 905-927. London: Elsevier Limited.

Dogrul A, Ossipov MH, Porreca F (2009) Differential mediation of descending pain facilitation and inhibition by spinal 5HT-3 and 5HT-7 receptors. Brain Res 1280:52-59.

Fields HL, Vanegas H, Hentall ID, Zorman G (1983a) Evidence that disinhibition of brain stem neurones contributes to morphine analgesia. Nature 306:684-686.

Fields HL, Bry J, Hentall I, Zorman G (1983b) The activity of neurons in the rostral medulla of the rat during withdrawal from noxious heat. J Neurosci 3:2545-2552.

Fields HL, Heinricher MM, Mason P (1991) Neurotransmitters in nociceptive modulatory circuits. Annu Rev Neurosci 14:219-245.

Fields HL, Malick A, Burstein R (1995) Dorsal horn projection targets of ON and OFF cells in the rostral ventromedial medulla. J Neurophysiol 74:1742-1759.

Fuccio C, Luongo C, Capodanno P, Giordano C, Scafuro MA, Siniscalco D, Lettieri B, Rossi F, Maione S, Berrino L (2009) A single subcutaneous injection of ozone prevents allodynia and decreases the over-expression of pro-inflammatory caspases in the orbito-frontal cortex of neuropathic mice. Eur J Pharmacol 603:42-49.

Gonçalves L, Almeida A, Pertovaara A (2007) Pronociceptive changes in response properties of rostroventromedial medullary neurons in a rat model of peripheral neuropathy. Eur J Neurosci 26:2188-2195.

Gu M, Wessendorf M (2007) Endomorphin-2-immunoreactive fibers selectively appose serotonergic neuronal somata in the rostral ventral medial medulla. J Comp Neurol 502:701-713.

Hassanzadeh P, Ahmadiani A (2006) Nitric oxide and c-Jun N-terminal kinase are involved in the development of dark neurons induced by inflammatory pain. Synapse 59:101-106.

Heinricher MM, Barbaro NM, Fields HL (1989) Putative nociceptive modulating neurons in the rostral ventromedial medulla of the rat: firing of on- and off-cells is related to nociceptive responsiveness. Somatosens Mot Res 6:427-439.

Hokfelt T, Zhang X, Wiesenfeld-Hallin Z (2006) Central consequences of peripheral nerve damage. In: Wall and Melzack's textbook of pain (McMahon S, Koltzenburg M, eds), pp 947-959. London: Elsevier.

Howard CV, Reed MG (1998) Unbiased stereology: three-dimensional measurement in microscopy. Oxford: BIOS.

Jalalvand E, Javan M, Haeri-Rohani A, Ahmadiani A (2008) Stress- and non-stress-mediated mechanisms are involved in pain-induced apoptosis in hippocampus and dorsal lumbar spinal cord in rats. Neuroscience 157:446-452.

Ji RR, Kohno T, Moore KA, Woolf CJ (2003) Central sensitization and LTP: do pain and memory share similar mechanisms? Trends Neurosci 26:696-705.

Kalyuzhny AE, Arvidsson U, Wu W, Wessendorf MW (1996) mu-Opioid and delta-opioid receptors are expressed in brainstem antinociceptive 
circuits: studies using immunocytochemistry and retrograde tracttracing. J Neurosci 16:6490-6503.

Kerr JF, Wyllie AH, Currie AR (1972) Apoptosis: a basic biological phenomenon with wide-ranging implications in tissue kinetics. Br J Cancer 26:239-257.

Kim SH, Chung JM (1992) An experimental model for peripheral neuropathy produced by segmental spinal nerve ligation in the rat. Pain 50:355-363.

Koltzenburg M, Lundberg LE, Torebjörk HE (1992) Dynamic and static components of mechanical hyperalgesia in human hairy skin. Pain 51:207-219.

Koltzenburg M, Torebjörk HE, Wahren LK (1994) Nociceptor modulated central sensitization causes mechanical hyperalgesia in acute chemogenic and chronic neuropathic pain. Brain 117:579-591.

Kwiat G, Basbaum AI (1992) The origin of brainstem noradrenergic and serotonergic projections to the spinal cord dorsal horn in the rat. Somatosens Mot Res 9:157-173.

Lawen A (2003) Apoptosis-an introduction. Bioessays 25:888-896.

Li Y, Dorsi MJ, Meyer RA, Belzberg AJ (2000) Mechanical hyperalgesia after an L5 spinal nerve lesion in the rat is not dependent on input from injured nerve fibers. Pain 85:493-502.

Liu CN, Raber P, Ziv-Sefer S, Devor M (2001) Hyperexcitability in sensory neurons of rats selected for high versus low neuropathic pain phenotype. Neuroscience 105:265-275.

Liu NJ, Chakrabarti S, Schnell S, Wessendorf M, Gintzler AR (2011) Spinal synthesis of estrogen and concomitant membrane estrogen receptor signaling regulate spinal kappa- and mu-opioid receptor heterodimerization and female-specific spinal morphine antinociception. J Neurosci 31:11836-11845.

Maione S, Siniscalco D, Galderisi U, de Novellis V, Uliano R, Di Bernardo G, Berrino L, Cascino A, Rossi F (2002) Apoptotic genes expression in the lumbar dorsal horn in a model neuropathic pain in rat. Neuroreport 13:101-106

McCleane GJ, Suzuki R, Dickenson AH (2003) Does a single intravenous injection of the 5HT3 receptor antagonist ondansetron have an analgesic effect in neuropathic pain? A double-blinded, placebo-controlled crossover study. Anesth Analg 97:1474-1478.

Mei XP, Xu H, Xie C, Ren J, Zhou Y, Zhang H, Xu LX (2011) Post-injury administration of minocycline: an effective treatment for nerve-injury induced neuropathic pain. Neurosci Res 70:305-312.

Meisner JG, Marsh AD, Marsh DR (2010) Loss of GABAergic interneurons in laminae I-III of the spinal cord dorsal horn contributes to reduced GABAergic tone and neuropathic pain after spinal cord injury. J Neurotrauma 27:729-737.

Michaelis M, Liu X, Jänig W (2000) Axotomized and intact muscle afferents but no skin afferents develop ongoing discharges of dorsal root ganglion origin after peripheral nerve lesion. J Neurosci 20:2742-2748.

Moore KA, Kohno T, Karchewski LA, Scholz J, Baba H, Woolf CJ (2002) Partial peripheral nerve injury promotes a selective loss of GABAergic inhibition in the superficial dorsal horn of the spinal cord. J Neurosci 22:6724-6731.

Mullen RJ, Buck CR, Smith AM (1992) NeuN, a neuronal specific nuclear protein in vertebrates. Development 116:201-211.

Ossipov MH, Hong Sun T, Malan P Jr, Lai J, Porreca F (2000) Mediation of spinal nerve injury induced tactile allodynia by descending facilitatory pathways in the dorsolateral funiculus in rats. Neurosci Lett 290:129-132.

Pertovaara A, Wei H, Hämäläinen MM (1996) Lidocaine in the rostroventromedial medulla and the periaqueductal gray attenuates allodynia in neuropathic rats. Neurosci Lett 218:127-130.

Polgár E, Gray S, Riddell JS, Todd AJ (2004) Lack of evidence for significant neuronal loss in laminae I-III of the spinal dorsal horn of the rat in the chronic constriction injury model. Pain 111:144-150.

Polgár E, Hughes DI, Arham AZ, Todd AJ (2005) Loss of neurons from laminas I-III of the spinal dorsal horn is not required for development of tactile allodynia in the spared nerve injury model of neuropathic pain. J Neurosci 25:6658-6666.

Popken GJ, Farel PB (1997) Sensory neuron number in neonatal and adult rats estimated by means of stereologic and profile-based methods. J Comp Neurol 386:8-15.

Porreca F, Burgess SE, Gardell LR, Vanderah TW, Malan TP Jr, Ossipov MH, Lappi DA, Lai J (2001) Inhibition of neuropathic pain by selective abla- tion of brainstem medullary cells expressing the mu-opioid receptor. J Neurosci 21:5281-5288.

Porreca F, Ossipov MH, Gebhart GF (2002) Chronic pain and medullary descending facilitation. Trends Neurosci 25:319-325.

Quaglino D, Ronchetti IP (2001) Cell death in the rat thymus: a minireview. Apoptosis 6:389-401.

Rahman W, Suzuki R, Webber M, Hunt SP, Dickenson AH (2006) Depletion of endogenous spinal 5-HT attenuates the behavioural hypersensitivity to mechanical and cooling stimuli induced by spinal nerve ligation. Pain 123:264-274.

Ramalho RM, Viana RJ, Low WC, Steer CJ, Rodrigues CM (2008) Bile acids and apoptosis modulation: an emerging role in experimental Alzheimer's disease. Trends Mol Med 14:54-62.

Reed MG, Howard CV (1998) Surface-weighted star volume: concept and estimation. J Microsc 190:350-356.

Ringkamp M, Eschenfelder S, Grethel EJ, Häbler HJ, Meyer RA, Jänig W, Raja SN (1999) Lumbar sympathectomy failed to reverse mechanical allodynia- and hyperalgesia-like behavior in rats with L5 spinal nerve injury. Pain 79:143-153

Rodrigues CM, Steer CJ (2001) The therapeutic effects of ursodeoxycholic acid as an anti-apoptotic agent. Expert Opin Investig Drugs 10:1243-1253.

Rodrigues CM, Fan G, Ma X, Kren BT, Steer CJ (1998) A novel role for ursodeoxycholic acid in inhibiting apoptosis by modulating mitochondrial membrane perturbation. J Clin Invest 101:2790-2799.

Rodrigues CM, Spellman SR, Solá S, Grande AW, Linehan-Stieers C, Low WC, Steer CJ (2002) Neuroprotection by a bile acid in an acute stroke model in the rat. J Cereb Blood Flow Metab 22:463-471.

Rodrigues CM, Sola S, Nan Z, Castro RE, Ribeiro PS, Low WC, Steer CJ (2003) Tauroursodeoxycholic acid reduces apoptosis and protects against neurological injury after acute hemorrhagic stroke in rats. Proc Natl Acad Sci U S A 100:6087-6092.

Sanchez V, Lucas M, Sanz A, Goberna R (1992) Decreased protein kinase C activity is associated with programmed cell death (apoptosis) in freshly isolated rat hepatocytes. Biosci Rep 12:199-206.

Schmued LC, Swanson LW, Sawchenko PE (1982) Some fluorescent counterstains for neuroanatomical studies. J Histochem Cytochem 30:123-128.

Schoemaker MH, Conde de la Rosa L, Buist-Homan M, Vrenken TE, Havinga R, Poelstra K, Haisma HJ, Jansen PL, Moshage H (2004) Tauroursodeoxycholic acid protects rat hepatocytes from bile acidinduced apoptosis via activation of survival pathways. Hepatology 39:1563-1573

Scholz J, Broom DC, Youn DH, Mills CD, Kohno T, Suter MR, Moore KA, Decosterd I, Coggeshall RE, Woolf CJ (2005) Blocking caspase activity prevents transsynaptic neuronal apoptosis and the loss of inhibition in lamina II of the dorsal horn after peripheral nerve. J Neurosci 25:7317-7323.

Sekiguchi M, Sekiguchi Y, Konno S, Kobayashi H, Homma Y, Kikuchi S (2009) Comparison of neuropathic pain and neuronal apoptosis following nerve root or spinal nerve compression. Eur Spine J 18:1978-1985.

Siniscalco D, Fuccio C, Giordano C, Ferraraccio F, Palazzo E, Luongo L, Rossi F, Roth KA, Maione S, de Novellis V (2007) Role of reactive oxygen species and spinal cord apoptotic genes in the development of neuropathic pain. Pharmacol Res 55:158-166.

Skagerberg G, Björklund A (1985) Topographic principles in the spinal projections of serotonergic and non-serotonergic brainstem neurons in the rat. Neuroscience 15:445-480.

Solá S, Aranha MM, Steer CJ, Rodrigues CM (2007) Game and players: mitochondrial apoptosis and the therapeutic potential of ursodeoxycholic acid. Curr Issues Mol Biol 9:123-138.

Sugimoto T, Bennett GJ, Kajander KC (1990) Transsynaptic degeneration in the superficial dorsal horn after sciatic nerve injury: effects of a chronic constriction injury, transection, and strychnine. Pain 42:205-213.

Suzuki R, Rahman W, Hunt SP, Dickenson AH (2004) Descending facilitatory control of mechanically evoked responses is enhanced in deep dorsal horn neurones following peripheral nerve injury. Brain Res 1019:68-76.

Suzuki R, Rahman W, Rygh LJ, Webber M, Hunt SP, Dickenson AH (2005) Spinal-supraspinal serotonergic circuits regulating neuropathic pain and its treatment with gabapentin. Pain 117:292-303. 
Vera-Portocarrero LP, Zhang ET, Ossipov MH, Xie JY, King T, Lai J, Porreca F (2006) Descending facilitation from the rostral ventromedial medulla maintains nerve injury-induced central sensitization. Neuroscience 140:1311-1320.

Wallace J (2007) Update on pharmacotherapy guidelines for treatment of neuropathic pain. Pain Headache Rep 11:208-214.

Ward A, Brogden RN, Heel RC, Speight TM, Avery GS (1984) Ursodeoxycholic acid: a review of its pharmacological properties and therapeutic efficacy. Drugs 27:95-131.

Wei F, Guo W, Zou S, Ren K, Dubner R (2008) Supraspinal glial-neuronal interactions contribute to descending pain facilitation. J Neurosci 28:10482-10495.

Wei F, Dubner R, Zou S, Ren K, Bai G, Wei D, Guo W (2010) Molecular depletion of descending serotonin unmasks its novel facilitatory role in the development of persistent pain. J Neurosci 30:8624-8636.

Wei H, Pertovaara A (1999) MK-801, an NMDA receptor antagonist, in the rostroventromedial medulla attenuates development of neuropathic symptoms in the rat. Neuroreport 10:2933-2937.

Whiteside GT, Munglani R (2001) Cell death in the superficial dorsal horn in a model of neuropathic pain. J Neurosci Res 64:168-173.

Winkler CW, Hermes SM, Chavkin CI, Drake CT, Morrison SF, Aicher SA (2006) Kappa opioid receptor (KOR) and GAD67 immunoreactivity are found in OFF and NEUTRAL cells in the rostral ventromedial medulla. J Neurophysiol 96:3465-3473.

Woolf CJ, Salter MW (2000) Neuronal plasticity: increasing the gain in pain. Science 288:1765-1769. 